\title{
PM.

\section{Impact of common SNPs in VEGF gene on the susceptibility of osteosarcoma}

\author{
G.L. Hu, G. Ma and J.H. Ming \\ Department of Orthopaedics, Renmin Hospital of Wuhan University, Wuhan, China
}

Corresponding author: J.H. Ming

E-mail: jianghua_ming@126.com

Genet. Mol. Res. 14 (4): 14561-14566 (2015)

Received May 31, 2015

Accepted August 25, 2015

Published November 18, 2015

DOI http://dx.doi.org/10.4238/2015.November.18.19

\begin{abstract}
We conducted a case-control study to assess the role of vascular endothelial growth factor (VEGF) $-634 \mathrm{G} / \mathrm{C},+936 \mathrm{C} / \mathrm{T}$, and $+1612 \mathrm{G} / \mathrm{A}$ genetic variations in the development of osteosarcoma in a Chinese population. This hospital-based case-control study examined 130 patients with osteosarcoma and 130 age- and gender-matched healthy controls from March 2011 and March 2013. Polymerase chain reaction-restriction fragment length polymorphism was applied to assess the VEGF $-634 \mathrm{G} / \mathrm{C},+936 \mathrm{C} / \mathrm{T}$, and $+1612 \mathrm{G} / \mathrm{A}$ gene polymorphisms. Using conditional regression analysis, individuals carrying the TT genotype of $V E G F+936 C / T$ were found to be correlated with an elevated risk of osteosarcoma, with an adjusted odds ratio (95\% confidence interval) of 2.70 (1.02-8.28). In conclusion, our study suggests that the TT genotype of $V E G F+936 \mathrm{C} / \mathrm{T}$ genetic variants is associated with an increased risk of osteosarcoma.
\end{abstract}

Key words: Polymorphism; Vascular endothelial growth factor; Osteosarcoma 


\section{INTRODUCTION}

Osteosarcoma is derived from mesenchymal tissues, which is a rare bone cancer that often occurs in children and adolescents (Ritter and Bielack, 2010). The annual incidence of osteosarcoma is approximately 3 in 1,000,000 individuals (Mirabello et al., 2009; Ottaviani and Jaffe, 2009). The development of osteosarcoma is a complex, multistep, and multifactorial process, and many environmental and genetic factors play an important role in the carcinogenesis process (Bovee and Hogendoorn, 2010; Powers et al., 2010). Several studies have suggested that genetic factors are involved in the development of osteosarcoma, such as glutathione S-transferase, vascular endothelial growth factor (VEGF), interleukin factor, and DNA repair genes (Tang et al., 2014; Wang et al., 2014; Zhi et al., 2014; Han et al., 2015).

Angiogenesis is the formation of new blood vessels from the preexisting endothelium, and it is a discrete event in carcinogenesis that is associated with the aggressive potential of a tumor (Hanahan and Folkman, 1996; Nakamura, et al., 2005). Accumulating evidence suggests that tumor growth is associated with increased angiogenesis and that new blood vessel formation is a fundamental step in tumor development and expansion (Mariani et al., 2012). VEGF is an important promoter of angiogenesis and is encoded by the VEGF gene (Hicklin and Ellis, 2005). Previous studies reported that VEGF gene polymorphisms are associated with the development and progression of solid tumors (Roy et al., 2006; Kushner and Bautch, 2013). There are 3 common single-nucleotide polymorphisms in the VEGF gene affecting plasma VEGF levels, including -634G/ $\mathrm{C},+936 \mathrm{C} / \mathrm{T}$, and $+1612 \mathrm{G} / \mathrm{A}$ (Watson et al., 2000). We conducted this case-control study to assess the role of the VEGF $-634 \mathrm{G} / \mathrm{C},+936 \mathrm{C} / \mathrm{T}$, and $+1612 \mathrm{G} / \mathrm{A}$ genetic variations in the development of osteosarcoma in a Chinese population.

\section{MATERIAL AND METHODS}

\section{Patients}

This hospital-based case-control study included 130 patients with osteosarcoma and 130 age- and gender-matched healthy controls from March 2011 and March 2013 in the Renmin Hospital of Wuhan University. Osteosarcoma patients were newly diagnosed and histopathologically confirmed independently by 2 gynecologic pathologists. The 130 controls were randomly selected from individuals who came to our hospital for regular health examination. The selection criteria for control subjects were: confirmation of lack of osteosarcoma, no history of any cancer, no family history of osteosarcoma in first-degree relatives, and a matched sex and age distribution with cases. All patients agreed to participate in the study and gave written informed consent according to the Declaration of Helsinki. The protocols of our study were approved by the Ethical Committee of the Renmin Hospital of Wuhan University. Demographic and clinical characteristics of patients and controls were obtained from medical records.

\section{DNA extraction and genotyping}

Venous blood samples were collected from the forearm of each participant and then placed in EDTA anticoagulant and centrifuged at $2700 \mathrm{rpm}$ for $10 \mathrm{~min}$ at room temperature. The collected supernatant was stored in a refrigerator maintained until further use. Polymerase 
chain reaction-restriction fragment length polymorphism was used to assess the VEGF $-634 \mathrm{G} / \mathrm{C},+936 \mathrm{C} / \mathrm{T}$, and +1612G/A gene polymorphisms. The primers for VEGF -634G/ C, +936C/T, and +1612G/A were as follows: 5'-GTAGCAAGAGCTCCAGAGAGAAGT-3' (forward) and 5'-TGGACGAAAAGTTTCAGTGCGACG-3' (reverse) for VEGF -634G/C, 5'-CTCGGTGATTTAGCAGCAAG-3' and 5'-CTCGGTGATTTAGCAGCAAG-3' for +936C/T, and 5'-CACATGCTGCACGCGCATCTC-3' and 5'-ACCCCAGGAAGGGGAGCAGGA-3' for +1612G/A. The amplification fragments for VEGF -634G/C, +936C/T and +1612G/A were 304, 208, and 217 base pairs, respectively. The restriction enzymes were BsmFI for VEGF -634G/C, Nlalll for VEGF $+936 \mathrm{C} / \mathrm{T}$, and Mnll for VEGF +1612G/A. PCRs were carried out with an initial denaturation step of $8 \mathrm{~min}$ at $94^{\circ} \mathrm{C}$, followed by 30 cycles at $94^{\circ} \mathrm{C}$ for $30 \mathrm{~s}$, annealing at $60^{\circ} \mathrm{C}$ for $30 \mathrm{~s}$, and extension at $72^{\circ} \mathrm{C}$ for $1 \mathrm{~min}$. The resulting DNA fragments were separated by $3.5 \%$ agarose gel electrophoresis and visualized under UV light after ethidium staining.

\section{Statistical analysis}

Statistically significant differences between cases and controls for demographic characteristics were assessed by Student's $t$-test and $c^{2}$ test. Departures from Hardy-Weinberg equilibrium for the VEGF $-634 \mathrm{G} / \mathrm{C}$, $+936 \mathrm{C} / \mathrm{T}$, and $+1612 \mathrm{G} / \mathrm{A}$ genotypes were evaluated by comparing the expected frequencies to the observed genotype frequencies using $X^{2}$ tests. Differences in genotypic frequencies between groups was assessed by the Pearson $X^{2}$ test and calculating the odds ratio, 95\% confidence intervals, and their corresponding $P$ values. All analyses were performed using SPSS 16.0 software version 16.0 (SPSS Inc., Chicago, IL, USA).

\section{RESULTS}

The distribution of the demographic characteristics in osteosarcoma patients and controls are shown in Table 1. No statistically significant differences were found between cases and controls in terms of gender and age at interview. Of the 130 osteosarcoma patients, $89(68.46 \%)$ patients were stage I-II, 94 (72.31\%) with tumors at the long tubular bones, while $28(21.54 \%)$ showed tumor metastasis. The tumor size of osteosarcoma was approximately $8.2 \pm 3.5 \mathrm{~cm}$.

\begin{tabular}{|c|c|c|c|c|c|c|}
\hline Characteristics & Osteosarcoma cases & $\%$ & Control subjects & $\%$ & $x^{2}$ value & $P$ value \\
\hline \multicolumn{7}{|l|}{ Gender } \\
\hline Female & 54 & 41.54 & 54 & 41.54 & & \\
\hline Male & 76 & 58.46 & 76 & 58.46 & 0.00 & 1.00 \\
\hline \multicolumn{7}{|l|}{ Age } \\
\hline$<20$ & 80 & 61.54 & 77 & 59.23 & & \\
\hline$\geq 20$ & 50 & 38.46 & 53 & 40.77 & 0.15 & 0.70 \\
\hline \multicolumn{7}{|l|}{ Stage } \\
\hline$I-I I$ & 89 & 68.46 & & & & \\
\hline III-IV & 41 & 31.54 & & & & \\
\hline \multicolumn{7}{|l|}{ Tumor location } \\
\hline Long tubular bones & 94 & 72.31 & & & & \\
\hline Axial skeleton & 36 & 27.69 & & & & \\
\hline Tumor size, cm & $8.2+3.5$ & & & & & \\
\hline \multicolumn{7}{|l|}{ Tumor metastasis } \\
\hline Positive & 28 & 21.54 & & & & \\
\hline Negative & 102 & 78.46 & & & & \\
\hline
\end{tabular}


Genotype distributions of VEGF gene polymorphisms in osteosarcoma patients and controls are shown in Table 2. We found that the genotype frequencies of VEGF $-634 \mathrm{G} / \mathrm{C}$, $+936 \mathrm{C} / \mathrm{T}$, and $+1612 \mathrm{G} / \mathrm{A}$ were in Hardy-Weinberg equilibrium in the control group (Table 2). By conditional regression analysis, individuals carrying TT genotype of VEGF +936C/T were found to be correlated with an elevated risk of osteosarcoma, and the adjusted odds ratio (95\% confidence interval) was 2.70 (1.02-8.28). However, the VEGF -634G/C and +1612G/A polymorphisms showed no significant association with the risk of osteosarcoma.

\begin{tabular}{|c|c|c|c|c|c|c|c|}
\hline Genotype & Cases & $\%$ & Controls & $\%$ & Hardy-Weinberg equilibrium & OR $(95 \% \mathrm{Cl})^{1}$ & $P$ value \\
\hline \multicolumn{8}{|c|}{ VEGF $-634 \mathrm{G} / \mathrm{C}$} \\
\hline GG & 42 & 32.31 & 46 & 35.38 & & 1.0 (Ref.) & - \\
\hline GC & 68 & 52.31 & 65 & 50.00 & & $1.15(0.65-2.04)$ & 0.62 \\
\hline $\mathrm{CC}$ & 20 & 15.38 & 18 & 14.62 & 0.51 & $1.22(0.53-2.80)$ & 0.61 \\
\hline $\mathrm{GC}+\mathrm{CC}$ & 88 & 67.69 & 83 & 64.62 & & $1.16(0.67-2.01)$ & 0.57 \\
\hline \multicolumn{8}{|c|}{ VEGF+936C/T } \\
\hline $\mathrm{CC}$ & 67 & 51.54 & 79 & 60.77 & & 1.0 (Ref.) & - \\
\hline $\mathrm{CT}$ & 47 & 36.15 & 44 & 33.85 & & $1.26(0.72-2.20)$ & 0.39 \\
\hline TT & 16 & 12.31 & 7 & 5.38 & 0.79 & $2.70(1.02-8.28)$ & 0.03 \\
\hline $\mathrm{CT}+\mathrm{TT}$ & 63 & 48.46 & 51 & 39.23 & & $1.46(0.86-2.46)$ & 0.13 \\
\hline \multicolumn{8}{|c|}{ VEGF+1612G/A } \\
\hline GG & 41 & 31.54 & 46 & 35.38 & & 1.0 (Ref.) & - \\
\hline GA & 61 & 46.92 & 60 & 46.15 & & $1.14(0.64-2.06)$ & 0.64 \\
\hline$A A$ & 28 & 21.54 & 24 & 18.46 & 0.57 & $1.31(0.62-2.76)$ & 0.44 \\
\hline $\mathrm{GA}+\mathrm{AA}$ & 89 & 68.46 & 84 & 64.62 & & $1.19(0.69-2.06)$ & 0.51 \\
\hline
\end{tabular}

${ }^{1}$ Adjusted for gender and age.

\section{DISCUSSION}

In this study, we investigated the association between VEGF genetic polymorphisms and the risk of osteosarcoma in a Chinese population. Our results suggested that the TT genotype of $V E G F+936 C / T$ was significantly associated with an increased risk of osteosarcoma.

Angiogenesis plays an important role in the development and metastasis of tumors, and the VEGF is a potent regulator of angiogenesis involved in the carcinogenesis of solid tumors (Roy et al., 2006; Kushner and Bautch, 2013). It is well-known that the VEGF gene is located on chromosome $6 \mathrm{p} 21.3$, and the protein consists of 8 exons, which can be alternatively spliced to generate a family of proteins (Vincenti et al., 1996). VEGF gene polymorphisms may influence the gene expression and affect plasma VEGF levels (Renner et al., 2000; Watson et al., 2000). Previous studies reported that VEGF gene polymorphisms may influence the development of many solid tumors, such as esophageal cancer, colorectal cancer, renal cell carcinoma, and breast cancer (Yao et al., 2014; Jannuzzi et al., 2015; Ma et al., 2015; Qasim et al., 2015). Qasim et al. (2015) conducted a case-control study to investigate the role of the VEGF +936C/T and $+404 \mathrm{C} / \mathrm{G}$ polymorphisms on the risk of esophageal cancer, and they found a significant association between the VEGF $+936 \mathrm{C} / \mathrm{T}$ and $+404 \mathrm{C} / \mathrm{G}$ polymorphisms and esophageal cancer risk. Jannuzzi et al. (2015) found that $+936 \mathrm{C} / \mathrm{T}$ and $+404 \mathrm{C} / \mathrm{G}$ polymorphisms may not play a role in the development of colorectal cancer. Ma et al. (2015) demonstrated that the VEGF -2578C/A polymorphism may be associated with the prognosis of renal cell carcinoma patients. Yao et al. (2014) conducted a meta-analysis of 8 case-control studies and found that the VEGF -634G/C polymorphism does not appear to carry a risk factor for breast cancer. The discrepancies between these studies may have been caused by differences in types of tumors, selection of patients, and control and sample sizes. 
For the correlation between VEGF gene polymorphisms and the risk of osteosarcoma, only 2 previous studies reported their association (Tie et al., 2014; Wang et al., 2014). Wang et al. (2014) conducted a case-control study in a Chinese population and found that the TT genotype of VEGF $+936 \mathrm{C} / \mathrm{T}$ genetic variants was related to an increased susceptibility to osteosarcoma. Tie et al. (2014) conducted a case-control study to assess the role of 5 common single-nucleotide polymorphisms in the VEGF gene in the development of osteosarcoma, and they found that the VEGF $-2578 \mathrm{C} / \mathrm{A}$ and $-634 \mathrm{G} / \mathrm{C}$ polymorphisms were associated with an increased risk of osteosarcoma. We also found that the TT genotype of VEGF $+936 \mathrm{C} / \mathrm{T}$ was associated with the pathogenesis of osteosarcoma. Further large-sample studies are greatly needed to confirm our findings.

In conclusion, our study suggests that the TT genotype of VEGF +936C/T genetic variants is associated with an increased risk of osteosarcoma, and further investigations of the role of VEGF gene polymorphisms on the risk of osteoporosis are needed.

\section{Conflicts of interest}

The authors declare no conflict of interest.

\section{REFERENCES}

Bovee JV and Hogendoorn PC (2010). Molecular pathology of sarcomas: Concepts and clinical implications. Virchows Archiv. 456: 193-199.

Han J, Deng W, Wang L and Qi W (2015). Null genotypes of glutathione S-transferase $\mathrm{m} 1$ and glutathione S-transferase $\theta 1$ are associated with osteosarcoma risk: a meta-analysis. Oncol. Lett. 9: 1912-1916.

Hanahan D and Folkman J (1996). Patterns and emerging mechanisms of the angiogenic switch during tumorigenesis. Cell 86: 353-364.

Hicklin DJ and Ellis LM (2005). Role of the vascular endothelial growth factor pathway in tumor growth and angiogenesis. J. Clin. Oncol. 23: 1011-1127.

Jannuzzi AT, Özhan G, Yanar HT and Alpertunga B (2015). VEGF gene polymorphisms and susceptibility to colorectal cancer. Genet. Test. Mol. Biomarkers 19: 133-137.

Kushner EJ and Bautch VL (2013). Building blood vessels in development and disease. Curr. Opin. Hematol. 20: 231-236.

Ma N, Li LW and Cheng JL (2015). Predictive value of vascular endothelial growth factor polymorphisms on the clinical outcome of renal cell carcinoma patients. Oncol. Lett. 9: 651-656.

Mariani BM, Trarbach EB, Ribeiro TC, Pereira MA, et al. (2012). Genotype analysis of the human endostatin variant p.D104N in benign and malignant adrenocortical tumors. Clinics 67: 95-98.

Mirabello L, Troisi RJ and Savage SA (2009). Osteosarcoma incidence and survival rates from 1973 to 2004: data from the surveillance, epidemiology, and end results program. Cancer 115: 1531-1543.

Nakamura Y, Yasuoka H, Tsujimoto M, Imabun S, et al. (2005). Lymph vessel density correlates with nodal status, VEGF-C expression, and prognosis in breast cancer. Breast Cancer Res. Treat. 91: 125-132.

Ottaviani G and Jaffe N (2009). The epidemiology of osteosarcoma. Cancer Treat. Res. 152: 3-13.

Powers M, Zhang W, Lopez-Terrada D, Czerniak BA, et al. (2010). The molecular pathology of sarcomas. Cancer Biomark. 9: 475-491.

Qasim I, Bhat IA, Masoodi KZ and Shah ZA (2015). Role of $+405 C>G$ and $+936 C>$ T polymorphisms of the vascular endothelial growth factor gene and risk of esophageal cancer in the Kashmiri population. Asian Pac. J. Cancer Prev. 16: 97-101.

Renner W, Kotschan S, Hoffmann C, Obermayer-Pietsch B, et al. (2000). A common 936 C/T mutation in the gene for vascular endothelial growth factor is associated with vascular endothelial growth factor plasma levels. J. Vasc. Res. 37: 443-448.

Ritter J and Bielack SS (2010) Osteosarcoma. Ann. Oncol. 21 (Suppl 7): vii320-vii325.

Roy H, Bhardwaj S and Ylä-Herttuala S (2006). Biology of vascular endothelial growth factors. FEBS Lett. 580: 2879-2887.

Tang YJ, Wang JL, Nong LG, Lan CG, et al. (2014). Associations of IL-27 polymorphisms and serum IL-27p28 levels with osteosarcoma risk. Medicine 93: e56.

Tie Z, Bai R, Zhai Z, Zhang G, et al. (2014). Single nucleotide polymorphisms in VEGF gene are associated with an increased risk of osteosarcoma. Int. J. Clin. Exp. Pathol. 7: 8143-8149. 
Vincenti V, Cassano C, Rocchi M and Persico G (1996). Assignment of the vascular endothelial growth factor gene to human chromosome 6p21.3. Circulation 93: 1493-1495.

Wang Z, Wen P, Luo X, Fang X, et al. (2014). Association of the vascular endothelial growth factor (VEGF) gene singlenucleotide polymorphisms with osteosarcoma susceptibility in a Chinese population. Tumour Biol. 35: 3605-3610.

Watson CJ, Webb NJ, Bottomley MJ and Brenchley PE (2000). Identification of polymorphisms within the vascular endothelial growth factor (VEGF) gene: correlation with variation in VEGF protein production. Cytokine 12: 1232-1235.

Yao W, Yan R, Ma L, Wan H, et al. (2014). Vascular endothelial growth factor gene polymorphism (-634G/C) and breast cancer risk. Tumour Biol. 35: 7793-7798.

Zhi LQ, Ma W, Zhang H, Zeng SX, et al. (2014). Association of RECQL5 gene polymorphisms and osteosarcoma in a Chinese Han population. Tumour Biol. 35: 3255-3259. 